\title{
Formation and growth of amorphous phases by solid-state reaction in elemental composites prepared by cold working
}

\author{
Michael Atzmon, John D. Verhoeven, ${ }^{\text {a) }}$ Edwin D. Gibson, ${ }^{a)}$ and W. L. Johnson \\ Keck Laboratory of Engineering Materials, California Institute of Technology, Pasadena, California 91125
}

(Received 3 July 1984; accepted for publication 18 August 1984)

Amorphous alloys of $\mathrm{Ni}-\mathrm{Zr}$ and $\mathrm{Cu}-\mathrm{Zr}$ have been synthesized by solid-state reaction of composite metal mixtures produced by mechanical deformation of metal powder mixtures and intercalated foil layers. The materials obtained were investigated by means of $x$-ray diffraction and differential scanning calorimetry. The results are compared with known data for thin films and rapidly quenched alloys.

Recently, Schwarz and Johnson ${ }^{1}$ showed that an amorphous alloy can form and grow during a relatively low-temperature solid-state reaction of evaporated thin-film layers of two polycrystalline metals. In a related experiment, $\mathrm{Koch}^{2}$ demonstrated that mechanical alloying of elemental $\mathrm{Ni}$ and $\mathrm{Nb}$ powders by high-energy ball milling for extended times leads to the formation of an amorphous alloy powder. A three-dimensional analogue of the thin-film diffusion couple experiment could offer a means of synthesizing bulk amorphous alloy structures. In an effort toward this goal, we have studied the reaction of mechanically deformed powder and foil mixtures of two crystalline metals. Mechanical deformation serves to (1) consolidate the binary mixture, (2) increase the interfacial area between the two metals, and (3) reduce at least one of the characteristic dimensions of the mixture. Point (2) is essential for achieving clean metal-metal interfaces free of oxides or surface contaminants present on the starting materials. Point (3) is required if completion of a reaction is to occur in practical times. A recent review article by $\mathrm{Bevk}^{3}$ describes the preparation, morphology, and properties of ultrafine filamentary composites. Such composites with filaments as thin as $50 \AA$ have been reported and are described and referenced in this article.

Two binary systems were chosen for this study: $\mathrm{Ni}-\mathrm{Zr}$ and $\mathrm{Cu}-\mathrm{Zr}$. Solid-state reactions in $\mathrm{Ni}-\mathrm{Zr}$ were reported previously by Clemens et al. ${ }^{4}$ The $\mathrm{Cu}-\mathrm{Zr}$ system was selected because of its similarity to $\mathrm{Ni}-\mathrm{Zr}$. The present study is the first report on the formation of amorphous $\mathrm{Cu}-\mathrm{Zr}$ by solidstate reaction.

Two different methods were used for sample preparation. $\mathrm{Ni}-\mathrm{Zr}$ was prepared by consolidating a thoroughly tumbled mixture of $40-\mu \mathrm{m}$ size $\mathrm{Ni}$ and $\mathrm{Zr}$ powders in an argon atmosphere, sealing it in vacuum in a stainless steel can, and subsequently cold rolling the sample plus can, reducing its thickness by a factor of 8 . Ni-Zr and $\mathrm{Cu}-\mathrm{Zr}$ samples were made by winding two annealed elemental foils of $\sim 10 \mu \mathrm{m}$ thickness in spiral form and then cold rolling them in a stainless steel jacket. For both methods, the foils obtained were removed from their containers and subsequently processed in 10-12 passes, each consisting of (1) folding the foil to double its thickness and (2) rolling it in between two $0.75-\mathrm{mm}$-thick stainless steel plates to the limit of the rolling mill.

\footnotetext{
a) Ames Laboratory and Department of Materials Science and Engineering, Iowa State University, Ames, Iowa 50011.
}

The scanning electron micrograph in Fig. 1 shows a cross section of a $\mathrm{Ni}-\mathrm{Zr}$ sample prepared by the powder metallurgical technique. Individual lamellae consisting of about 1000-Å-thick Ni and $Z r$ layers can be seen. Figure 2(a) shows an $\mathrm{x}$-ray diffraction pattern of an as-rolled $\mathrm{Ni}_{62} \mathrm{Zr}_{38}$ composite, taken with a vertical diffractometer in reflection geometry. In this configuration, the $\mathrm{x}$-ray scattering vector $K$ is perpendicular to the foil surface. The Scherrer formula ${ }^{5}$ allows one to estimate the typical size $t$ (parallel to $K$ ) of an individual microcrystal as

$$
t=0.9 \lambda / B \cos \theta,
$$

where $\lambda$ is the wavelength of the radiation, $B$ is the linewidth, and $2 \theta$ is the scattering angle. This microcrystal size is a lower bound on the lamella thickness since the thickness of the lamella must contain at least one microcrystal. The instrumental line broadening was measured with a single crystal and found to be $0.15^{\circ}$. After appropriate account of the instrumental broadening was taken, $t$ values of 500 and 600 $\AA$ were obtained for $\mathrm{Zr}$ and $\mathrm{Ni}$, respectively. For the copper in $\mathrm{Cu}-\mathrm{Zr}, t$ is equal to $250 \AA$. In both $\mathrm{Ni}-\mathrm{Zr}$ and $\mathrm{Cu}-\mathrm{Zr}$ composites, strong texture is observed. For $\mathrm{Ni}$ and $\mathrm{Cu}$, the relative intensity of the (220) lines is higher than expected for the diffraction pattern of a randomly distributed powder. This is consistent with the description of the texture in cold-rolled face centered cubic metals given in the literature. ${ }^{6}$ Among the Bragg peaks corresponding to zirconium, the $(100)$ is barely present before the reaction while the $(002)$ is relatively intense.

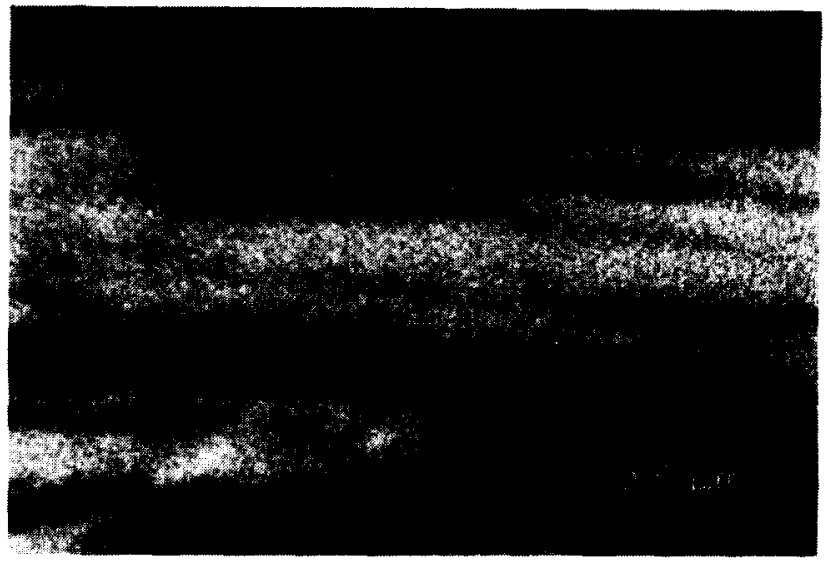

FIG. 1. Scanning electron micrograph of a cross section of a $\mathrm{Ni}-\mathrm{Zr}$ composite foil as rolled. 


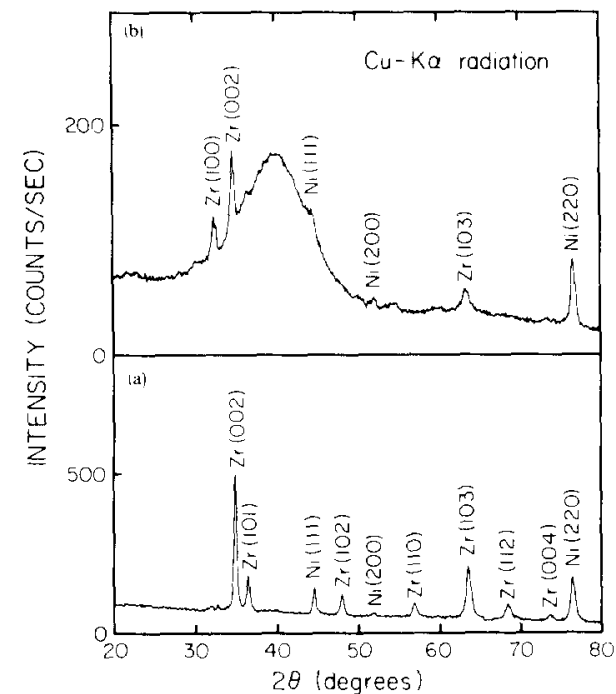

FIG. 2. $\mathrm{X}$-ray diffraction pattern for a $\mathrm{Ni}_{62} \mathrm{Zr}_{38}$ composite (a) as rolled and (b) reacted at $260^{\circ} \mathrm{C}$ for $14 \mathrm{~h}$.

Prior to annealing the sample foils were sealed under vacuum in pyrex tubes containing $\mathrm{Zr}$ getters, which were separately heated above $500^{\circ} \mathrm{C}$ for $10 \mathrm{~h}$ while the samples remained at ambient temperature. Then the samples were annealed at temperatures ranging from 250 to $370{ }^{\circ} \mathrm{C}$ for times of 1-32 h. For both $\mathrm{Ni}-\mathrm{Zr}$ and $\mathrm{Cu}-\mathrm{Zr}$, crystalline intermetallic compounds were obtained at annealing temperatures above $280^{\circ} \mathrm{C}$, as observed with x-ray diffraction. Figure 2 (b) shows the $x$-ray diffraction pattern in the same geometry as in Fig. 2(a) for a $\mathrm{Ni}_{62} \mathrm{Zr}_{38}$ sample, reacted at $260^{\circ} \mathrm{C}$ for $14 \mathrm{~h}$. A broad diffuse diffraction maximum (width $\left.\sim 10^{\circ}\right)$ is observed in a range of $K$ values, in which no Bragg peaks were present before the reaction. The original $\mathrm{Ni}$ and $\mathrm{Zr}$ phases are not completely reacted, as can be seen from the remaining peaks. The fraction of unreacted material can be estimated from the ratio of the area under the Bragg peaks to the area under the diffuse maximum. It is approximately $20 \%$. For a reaction time of $32 \mathrm{~h}$ at the same temperature, little further growth of the amorphous phase is observed, but one or more crystalline intermetallic compounds are formed. There still remains some elemental material. The incompleteness of the reaction can have several causes: surface oxides or other contaminants may be present on some interfaces and act as diffusion barriers; the occurrence of several adjacent layers of the same metal could lead to rather thick regions of one metal. Thus much longer times would be required to react these regions. In such long times, crystalline compounds are observed to form and thus a completely amorphous by-product is precluded.

It should be noted that the original Bragg peak intensities do not all decrease at the same rate during the reaction. In particular, the $\mathrm{Zr}(110)$ and the $\mathrm{Ni}(111)$ show the fastest rate of decrease while the $\mathrm{Ni}(220)$ increases slightly. The latter observation was shown to be related to preferred (220) coarsening of $\mathrm{Ni}$ grains by separate annealing of cold rolled
$\mathrm{Ni}$ foils at $260^{\circ} \mathrm{C}$.

Differential scanning calorimetry was performed on several samples of $\mathrm{Ni}_{x} \mathrm{Zr}_{1-x}\left(x=62,68\right.$; reacted at $270{ }^{\circ} \mathrm{C}$ for $8-16 \mathrm{~h}$ ) and $\mathrm{Cu}_{60} \mathrm{Zr}_{40}$ reacted at $275^{\circ} \mathrm{C}$ for $16 \mathrm{~h}$. For all $\mathrm{Ni}-\mathrm{Zr}$ samples, an exothermic peak at $550-565^{\circ} \mathrm{C}$ was obtained for a heating rate of $20^{\circ} \mathrm{C} / \mathrm{min}$. X-ray diffraction patterns of a sample heated to $500^{\circ}$ and cooled rapidly show the presence of a new crystalline intermetallic compound and a remaining amorphous phase. This compound is likely to be a result of the completion of the reaction of the pure zirconium and nickel. After heating the sample to $570^{\circ} \mathrm{C}$ and cooling it down, the $\mathrm{x}$-ray diffraction pattern shows no remaining amorphous material and a new set of Bragg peaks. We therefore attribute the exothermic peak to the crystallization of the amorphous phase. Our result for the crystallization temperature $T_{x}$ is in close agreement with Dong et al. ${ }^{7}$ who report that for $\mathrm{Ni}-\mathrm{Zr}$ metallic glasses produced by rapid quenching, $T_{x}$ has a maximum as a function of composition equal to $575^{\circ} \mathrm{C}$ at 64 at. \% nickel. Preliminary results for $\mathrm{Cu}_{60} \mathrm{Zr}_{40}$ yield an endothermic peak at $440^{\circ} \mathrm{C}$ and two sharp exothermic peaks at 475 and $500^{\circ} \mathrm{C}$, respectively. The endothermic peak is characteristic of a glass transition. Kerns et $a l^{8}$ report for the rapidly quenched metallic glass $\mathrm{Cu}_{60} \mathrm{Zr}_{40}$ a glass transition temperature $T_{g}$ of $450^{\circ} \mathrm{C}$ and a crystallization temperature of $490^{\circ} \mathrm{C}$. Our values of $T_{g}$ and $T_{x}$ are again in close agreement with those obtained for rapidly quenched glasses.

In summary, we have demonstrated the feasibility of solid-state reactions for synthesizing amorphous alloys in three dimensions. For the first time, thermal analysis of the product of such reaction has become possible, and the results indicate that the crystallization and glass transition temperatures of the amorphous phases formed by respectively solid-state reaction and rapid quenching of an alloy of similar composition are nearly identical.

The authors appreciate the assistance of Mr. Patrick Koen in the scanning electron microscopy. One of the authors (M.A) would like to acknowledge the financial support of the Standard Oil Company. This work was supported by the U.S. Department of Energy, through Project Agreement No. DE-AT03-81ER10870, contract DE-AM03-76SF00767, and through the Ames Laboratory.

'R. B. Schwarz and W. L. Johnson, Phys. Rev. Lett. 51, 415 (1983).

${ }^{2}$ C. C. Koch, O. B. Cavin, C. G. McKamey, and J. O. Scarbrough, Appl. Phys. Lett. 43, 1017 (1983).

${ }^{3} \mathbf{J}$. Bevk, in Annual Review of Materials Science, edited by R. A. Huggins, R. H. Bube, and D. A. Vermilyea (Annual Review Inc., Palo Alto, 1983), Vol. 13.

${ }^{4}$ B. M. Clemens, W. L. Johnson, and R. B. Schwarz, J. Non-Cryst. Solids 61\&62, $817(1983)$.

${ }^{5}$ A. Guinier, X-Ray Diffraction (Freeman, San Francisco, 1963), p. 124.

${ }^{6} \mathrm{C}$. S. Barret and T. B. Massalski, Structure of Metals (Pergamon, Oxford, 1980), p. 555.

${ }^{7}$ Y. D. Dong, G. Gregan, and M. G. Scott, J. Non-Cryst. Solids 43, 403 \{1981\}.

${ }^{8}$ A. J. Kerns, D. E. Polk, R. Ray, and B. C. Giessen, Mater. Sci. Eng. 38, 49 (1979). 